JAMP: Jurnal Adminitrasi dan Manajemen Pendidikan Volume 1 Nomor 1 Maret 2018, Hal : 16-21

Tersedia Online di http://journal2.um.ac.id/index.php/jamp/ ISSN $x x x x-x x x x$ (online)

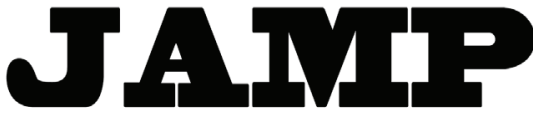

JURNAL ADMINISTRASI DAN MANAJEMEN PENDIDIKAN

\title{
STRATEGI PREVENTIF MENUMBUHKAN KEDISIPLINAN PEGAWAI KANTOR PERPUSTAKAAN DAN ARSIP PEMERINTAH
}

\author{
Suhartama Febrizki Badrur Ramadhani \\ Imron Arifin \\ A. Yusuf Sobri \\ febrizkisuhartama@gmail.com \\ Universitas Negeri Malang, Jl. Semarang No. 5 Malang 65145
}

\begin{abstract}
The purpose of this study describes employee data, scope of employee duties, and preventive strategies to grow the discipline employees of the Office of Library and Archives Probolinggo City. This research uses qualitative approach of case study type with research location at Office of Library and Archives of the Government of Probolinggo. Research findings include: (1) regarding employee data, the number of employees as many as 34 employees, and the last level of education undertaken by employees is divided into S2, S1, D3, SMA/SMK/SMEA, and SD. (2) The scope of work consists of head office, head of administrative sub-division, head of service and library management, head of section coaching and development of libraries and archives, head of the acquisition and management of the archives. (3) Preventive strategy by evaluating employee performance targets, holding coaching to all staff every month, and every year there Employee Performance Goals.
\end{abstract}

Keywords: Preventive strategies, discipline, employees, Office of Library and Archives of the Government

\begin{abstract}
Abstrak: Tujuan penelitian ini mendeskripsikan mengenai data pegawai, lingkup tugas pegawai, dan strategi preventif untuk menumbuhkan kedisiplinan pegawai di Kantor Perpustakaan dan Arsip Pemerintah Kota Probolinggo. Penelitian ini menggunakan pendekatan kualitatif jenis studi kasus dengan lokasi penelitian di Kantor Perpustakaan dan Arsip Pemerintah Kota Probolinggo. Temuan penelitian antara lain: (1) mengenai data pegawai, jumlah pegawai sebanyak 34 pegawai, dan jenjang pendidikan terakhir yang ditempuh oleh para pegawai dibedakan menjadi S2, S1, D3, SMA/SMK/SMEA, dan SD. (2) Lingkup tugas terdiri kepala kantor, kepala sub-bagian tata usaha, kepala seksi pelayanan dan pengelolaan perpustakaan, kepala seksi pembinaan dan pengembangan perpustakaan dan arsip, kepala seksi akuisisi dan pengelolaan arsip. (3) Strategi preventif dengan melakukan evaluasi terhadap target kinerja pegawai, diadakannya pembinaan kepada seluruh pegawai setiap bulannya, dan tiap tahun ada SKP (Sasaran Kinerja Pegawai).
\end{abstract}

Kata Kunci: Strategi preventif, disiplin, pegawai, Kantor Perpustakaan dan Arsip Pemerintah

Sumber daya manusia merupakan salah satu faktor yang sangat penting dalam suatu organisasi. Sumber daya manusia hendaknya dikelola secara efektif untuk mendukung organisasi dalam mencapai tujuan atau visi yang telah ditentukannya. Dengan kata lain, keberhasilan atau kemunduran sebuah organisasi ditentukan oleh kualitas serta pemanfaatan sumber daya manusia yang bekerja di dalamnya. Begitu pula dalam suatu organisasi pemerintahan, dibutuhkan sumber daya manusia yang selalu memberikan pelayanan kepada masyarakat secara jujur, profesional dan adil.

Keberadaan sumber daya manusia ini untuk mendukung terwujudnya pembangunan negara melalui tugas negara yang diembannya sesuai dengan tempat dan posisi pegawai tersebut bekerja. Kedudukan dan peranan sumber daya manusia yang begitu penting sehingga pegawai dituntut untuk 
mencurahkan segala daya dan tenaganya untuk menciptakan kinerja terbaiknya. Kinerja setiap pegawai akan menentukan tingkat produktivitas sebuah organisasi tersebut. Semakin banyak pegawai yang memiliki kinerja maksimal maka produktivitas organisasi secara keseluruhan akan meningkat sehingga visi dari organisasi bisa terwujud. Pada hakikatnya kinerja pegawai merupakan prestasi yang dicapai oleh seseorang dalam melaksanakan tugasnya atau pekerjaannya sesuai dengan standar dan kriteria yang ditetapkan untuk pekerjaan itu. Pegawai dituntut untuk melakukan setiap tugasnya secara efektif dan efisien. Tentunya banyak faktor yang mempengaruhi kinerja pegawai, salah satunya adalah disiplin kerja pegawai.

Disiplin kerja yang baik menunjukkan besarnya tanggung jawab seorang pegawai terhadap tugastugas yang diembannya. Rasa disiplin haruslah datang dari diri pribadi pegawai itu sendiri sehingga pegawai tersebut senantiasa melakukan tugasnya dengan penuh rasa tanggung jawab dan sebaik mungkin. Disiplin merupakan salah satu hal yang harus terus menerus dijaga dan ditingkatkan secara terus menerus agar pegawai tersebut terbiasa bekerja dengan penuh kedisiplinan. Banyak faktor yang dapat mempengaruhi tegak tidaknya suatu disiplin kerja dalam suatu Instansi Pemerintah. Faktor-faktor tersebut antara lain: (1) Besar kecilnya pemberian kompensasi, (2) Ada tidaknya keteladanan pimpinan dalam perusahaan, (3)Ada tidaknya aturan pasti yang dapat dijadikan pegangan, (4) Keberanian pimpinan dalam mengambil tindakan, (5) Ada tidaknya pengawasan pimpinan, (6) Ada tidaknya perhatian kepada pegawai, (7) Diciptakan kebiasaan-kebiasaan yang mendukung tegaknya disiplin (Saydam, 2000:202).

Pegawai merupakan penggerak kegiatan dalam suatu instansi atau lembaga. Kegiatan yang dilakukan pegawai memerlukan petunjuk kerja dari instansi atau lembaganya agar pelaksanaannya sesuai dengan yang direncanakan sebelumnya, dan harus didukung dengan peraturan sehingga menciptakan suatu disiplin kerja. Fachri (2009:88) dalam penelitian yang dilakukan menghasilkan faktor-faktor yang mempengaruhi disiplin kerja pegawai meliputi tiga hal, yaitu (a) tujuan dan kemampuan karyawan; (b) teladan pimpinan; dan (c) balas jasa dan kesejahteraan. Setyaningdyah (2013:140) dalam hasil penelitian menunjukkan bahwa disiplin kerja secara signifikan dipengaruhi oleh kompetensi Sumber Daya Manusia dan komitmen organisasi, ditemukan juga bahwa ada pengaruh yang signifikan antara komitmen organisasi, kepemimpinan transaksional, dan disiplin kerja pegawai dengan kinerja pegawai.

Disiplin sangat penting untuk pertumbuhan organisasi atau instansi. Disiplin digunakan terutama untuk memotivasi pegawai agar dapat mendisiplinkan diri. Sebagaimana kemampuan yang dimiliki manusia atau pegawai, namun jika tidak diimbangi dengan pemahaman terhadap disiplin kerja yang tinggi, maka tugas dan pekerjaannya yang dilaksanakan tidak akan menghasilkan kinerja yang baik, bahkan mungkin akan dapat menimbulkan kegagalan dalam tercapainya tujuan dalam organisasi. Pemahaman pegawai yang kurang terhadap peraturan serta kurang tegasnya hukuman yang diberikan akan membuat pegawai sering melakukan pelanggaran dan mengakibatkan kurang disiplinnya pegawai. Tindakan yang kurang disiplin tersebut ditunjukkan dengan sikap mengobrol di ruang kerja, keluar dari ruang kerja, seringnya absen, dan dalam berpakaian tidak rapi serta menunjukkan sikap yang kurang sopan.

Membentuk disiplin pegawai yang baik, pimpinan harus menerapkan strategi agar disiplin para pegawai tetap baik dan tidak menurun. Strategi yang baik dan tepat dalam hal menjaga disiplin pegawai akan menghasilkan sikap disiplin yang baik dan mencerminkan besarnya tanggung jawab seorang pegawai terhadap tugas-tugas yang diberikan. Hal ini mendorong semangat kerja para pegawai sehingga tujuan instansi atau lembaga dapat terwujud dengan baik.

Tujuan dari penelitian ini adalah untuk mendeskripsikan data pegawai Kantor Perpustakaan dan Arsip Pemerintah Kota Probolinggo, mendeskripsikan lingkup tugas pegawai Kantor Perpustakaan dan Arsip Pemerintah Kota Probolinggo dan mendeskripsikan strategi preventif menumbuhkan kedisiplinan pegawai Kantor Perpustakaan dan Arsip Pemerintah Kota Probolinggo. 


\section{METODE}

Pendekatan yang digunakan dalam penelitian ini adalah pendekatan kualitatif. Pendekatan kualitatif digunakan untuk menemukan sesuatu dalam pengamatan peneliti di lapangan. Jenis penelitian ini menggunakan penelitian studi kasus untuk meneliti fenomena yang terjadi di lapangan. Penelitian studi kasus adalah suatu metode penelitian yang memusatkan pada suatu kasus dan mengkajinya secara mendalam. Lokasi penelitian ini adalah Kantor Perpustakaan dan Arsip Pemerintah Kota Probolinggo. Kantor Perpustakaan dan Arsip Pemerintah Kota Probolinggo sebagai lembaga teknis daerah yang mempunyai tugas membantu walikota dalam penyelenggaraan pemerintah kota di bidang kearsipan daerah.

Pelaksanaan penelitian ini peneliti datang langsung ke Kantor Perpustakaan dan Arsip Pemerintah Kota Probolinggo sebagai objek penelitian, dan melakukan pengambilan data kepada para informan dengan menerapakan teknik-teknik pengambilan data pada penelitian kualitatif. Cara tersebut dilaksanakan oleh peneliti karena peneliti ingin mengetahui strategi preventif untuk menumbuhkan kedisiplinan pegawai tersebut.

Informan pada penelitian ini adalah Kepala Perpustakaan dan Arsip sebagai penanggung jawab kantor perpustakaan dan arsip pemerintah kota probolinggo; kepala sub bagian tata usaha; pengolah data TU dan kepegawaian, dan Staf. Sumber tambahan pada penelitian ini berupa dokumen atau sumber tertulis. Sumber tersebut dapat berupa foto-foto dan juga arsip surat-surat penting.

Teknik dalam pengumpulan data pada penelitian ini antara lain: teknik wawancara, teknik observasi, dan teknik dokumentasi. Sedangkan analisis data penelitian ini meliputi: (1) Reduksi data yaitu data yang diperoleh muncul dari catatan-catatan tertulis di lapangan, data dihimpun dari berbagai sumber di lapangan, disederhanakan dan disimpulkan; (2) Proses penyederhanaan data yaitu penyerdehanaan data yang diperoleh di lokasi penelitian yang berkenaan dengan strategi preventif menumbuhkan kedisiplinan pegawai; (3) Penyajian data yaitu diperlukan untuk memudahkan pemahaman peneliti tentang apa yang terjadi. Data yang telah disajikan tersebut kemudian diseleksi dan disederhanakan; dan (4) Langkah akhir yaitu menarik kesimpulan atau verifikasi yaitu Pada tahap ini merupakan proses di mana peneliti mampu menggambarkan tentang strategi preventif menumbuhkan kedisiplinan pegawai.

\section{HASIL}

\section{Data Pegawai Kantor Perpustakaan dan Arsip Pemerintah Kota Probolinggo}

Data Pegawai Kantor Perpustakaan dan Arsip Pemerintah Kota Probolinggo yaitu: (1) Pegawai Kantor Perpustakaan dan Arsip Pemerintah Kota Probolinggo memiliki jumlah pegawai sebanyak 34 pegawai; (2) mengenai jenjang pendidikan terakhir yang ditempuh oleh para pegawai Kantor Perpustakaan dan Arsip Pemerintah Kota Probolinggo dapat dibedakan menjadi S2 sebanyak 4 orang, S1 sebanyak 2 orang, D3 sebanyak 4 orang, SMA/SMK/SMEA sebanyak 23 orang, dan SD sebanyak 1 orang; dan (3) data pegawai berdasarkan data kepangkatan/golongan dibedakan menjadi Pembina Tk.I / IVb , Pembina / IVa, Penata Tk.I / IIId, Penata / IIIc, Penata Muda Tk.I / IIIb, Penata Muda / IIIa, Pengatur Tk.I / IId, Pengatur / IIc, Pengatur Muda Tk.I / IIb, Pengatur Muda / IIa.

\section{Lingkup Tugas Pegawai Kantor Perpustakaan Dan Arsip Pemerintah Kota Probolinggo}

Pegawai Kantor Perpustakaan dan Arsip Pemerintah Kota Probolinggo memiliki tugas dan fungsi yang berbeda-beda sesuai dengan jabatan yang diterima. Adapun susunan stuktur organisasi di Kantor Perpustakaan dan Arsip Pemerintah Kota Probolinggo: (1) Kepala Kantor dipimpin oleh Ir.Nuril Anwar, M.MA, (2) Kepala Sub-bagian Tata Usaha dipimpin oleh Sri Wahyuni, S.E, M.Si, (3) Kepala seksi pelayanan dan pengelolaan perpustakaan dipimpin oleh Nura'i, S.Pd, M.Si, (4) Kepala seksi pembinaan dan pengembangan perpustakaan dan arsip dipimpin oleh Nur Fajari, S.Pd, MM, dan (5) Kepala seksi akuisisi dan pengelolaan arsip dipimpin oleh Dwi Hendri Wuryani. 


\section{Strategi Preventif Menumbuhkan Kedisiplinan Pegawai Kantor Perpustakaan dan Arsip Pemerintah Kota Probolinggo}

Tingkat disiplin kerja yang dilakukan pegawai Kantor Perpustakaan dan Arsip Kota Probolinggo sudah tinggi, dalam membentuk kedisiplinan pegawai diperlukan sebuah strategi agar kedisiplinan pegawai Kantor Perpustakaan dan Arsip Kota Probolinggo tidak mengalami penurunan. Banyak strategi yang dilakukan oleh Kepala Kantor Perpustakaan dan Arsip Kota Probolinggo, salah satu strategi yang dilakukan yaitu dengan melakukan evaluasi terhadap target kinerja pegawai, diadakannya pembinaan kepada seluruh staf dan pegawai setiap bulannya, dan tiap tahun ada SKP (Sasaran Kinerja Pegawai). Penerapan strategi yang dilakukan yaitu dengan cara mengevaluasi target kinerja pegawai. Hal ini diharapkan agar pegawai tidak mengalami penurunan kedisiplinannya dalam menjalankan tugas dan fungsi sebagai pegawai kantor Perpustakaan dan Arsip Kota Probolinggo. SKP itu sendiri mengenai target kinerja yang harus dicapai pegawai dan setiap pegawai berbeda-beda cara penilaian SKP-nya.

\section{PEMBAHASAN}

\section{Data Pegawai Kantor Perpustakaan dan Arsip Pemerintah Kota Probolinggo}

Berdasarkan Profil Kantor Perpustakaan dan Arsip Pemerintah Kota Probolinggo memiliki jumlah pegawai sebanyak 34 pegawai yaitu: 1 (satu) Kepala Kantor, 1 (satu) Kepala Sub Bagian TU, 3 (tiga) orang Kepala Seksi, 5 (lima) orang tenaga Fungsional dan 24 (dua puluh empat) orang Staf. Jumlah pegawai keseluruhan ada 34 orang, yang terdiri dari 25 orang Pegawai Negeri Sipil (PNS), 8 orang Tenaga Harian Lepas (THL) dan 1 orang Tenaga kontrak. Menurut data daftar pegawai yang diperoleh dari Kantor Perpustakaan dan Arsip Pemerintah Kota Probolinggo, jenjang pendidikan terakhir yang ditempuh oleh para pegawai kantor Perpustakaan dan Arsip Pemerintah Kota Probolinggo dibedakan menjadi S2, S1, D3, SMA/SMK/SMEA, dan SD.

Profil pegawai Kantor Perpustakaan dan Arsip Pemerintah Kota Probolinggo sudah sesuai dengan Standar Nasional Perpustakaan Nomor 003 Tahun 2011 tentang Standar Nasional Perpustakaan Umum Kabupaten/Kota menjelaskan "Kualifikasi kepala perpustakaan sekurang-kurangnya berlatar belakang pendidikan S1/Diploma perpustakaan atau S1/Diploma non perpustakaan dengan pelatihan bidang perpustakaan". Status tenaga pengelola perpustakaan menurut Standar Nasional Perpustakaan Nomor 003 Tahun 2011 tentang Standar Nasional Perpustakaan Umum Kabupaten/Kota terdiri dari "Pustakawan, tenaga teknis, dan tenaga pendukung yang berstatus tetap atau honorer". Profil pegawai Kantor Perpustakaan dan Arsip Pemerintah Kota Probolinggo memiliki pegawai dengan lulusan S2, S1, D3, SMA/SMK/SMEA, dan SD.

\section{Lingkup Tugas Pegawai Kantor Perpustakaan dan Arsip Pemerintah Kota Probolinggo}

Pegawai Kantor Perpustakaan dan Arsip Pemerintah Kota Probolinggo memiliki tugas dan fungsi yang berbeda-beda sesuai dengan jabatan yang diterimanya, untuk tugas dan fungsi pegawai Kantor Perpustakaan dan Arsip Kota Probolinggo sudah disesuaikan menurut Peraturan Walikota Probolinggo Nomor 100 Tahun 2016 tentang Kedudukan, Susunan Organisasi, Uraian Tugas dan Fungsi serta Tata Kerja Dinas Perpustakaan dan Kearsipan Kota Probolinggo menjelaskan bahwa susunan pegawai Kantor Perpustakaan dan Arsip Pemerintah Kota Probolinggo terdiri dari: (a) Kepala kantor, (b) Sekretariat yang membawahi sub bagian tata usaha dan sub bagian program dan keuangan, (c) Bidang perpustakaan yang membawahi seksi pengolahan dan pelestarian bahan pustaka, serta seksi layanan dan otomasi perpustakaan, (d) Bidang kearsipan yang membawahi seksi pengelolaan arsip dinamis, dan seksi pengelolaan arsip statis, (e) Bidang pembinaan dan pemasyarakatan perpustakaan dan kearsipan yang membawahi seksi pembinaan dan pengembangan perpustakaan, seksi pembinaan dan pengembangan kearsipan, dan seksi pemasyarakatan perpustakaan dan kearsipan. 


\section{Strategi Preventif Menumbuhkan Kedisiplinan Pegawai Kantor Perpustakaan dan Arsip Pemerintah Kota Probolinggo}

Tingkat disiplin kerja yang dilakukan pegawai Kantor Perpustakaan dan Arsip Kota Probolinggo sudah tinggi, hal tersebut terlihat dalam daftar hadir pegawai dan dalam kegiatan bekerja para pegawai. Hal ini sesuai dengan teori yang dipaparkan oleh Sjarif (dalam Hidayatullah, 2010:45) disiplin pada hakikatnya adalah "suatu ketaatan yang sungguh-sungguh yang didukung oleh kesadaran untuk menunaikan tugas kewajiban serta berperilaku sebagaimana mestinya menurut aturan-aturan atau tata kelakuan yang seharusnya berlaku di dalam suatu lingkungan tertentu". Dalam membentuk kedisiplinan pegawai, diperlukan sebuah strategi agar kedisiplinan pegawai Kantor Perpustakaan dan Arsip Kota Probolinggo tidak mengalami penurunan. Banyak strategi yang dilakukan oleh Kepala Kantor Perpustakaan dan Arsip Kota Probolinggo, salah satu strategi yang dilakukan yaitu dengan melakukan evaluasi terhadap target kinerja pegawai, diadakannya pembinaan kepada seluruh staf dan pegawai setiap bulannya, dan tiap tahun ada SKP (Sasaran Kinerja Pegawai). Penerapan strategi yang dilakukan yaitu dengan cara mengevaluasi target kinerja pegawai. Hal ini diharapkan agar pegawai tidak mengalami penurunan kedisiplinannya dalam menjalankan tugas dan fungsi sebagai pegawai kantor Perpustakaan dan Arsip Kota Probolinggo. Penerapan strategi ini dilakukan dengan cara penilaian SKP (Sasaran Kinerja Pegawai). SKP itu sendiri mengenai target kinerja yang harus dicapai pegawai dan setiap pegawai berbeda-beda cara penilaian SKP-nya.

Untuk meningkatkan kedisiplinan para pegawainya, bapak Ir. Nuril Anwar, M.MA selaku kepala Kantor Perpustakaan dan Arsip Pemerintah Kota Probolinggo memberikan penghargaan kepada para pegawainya yaitu dengan mengirimkan pegawai yang berprestasi BKD sehingga pegawai tersebut akan mendapatkan hadiah sesuai dengan hasil kinerja yang selama ini dilakukannya, dengan pemberian penghargaan ini, diharapkan para pegawai kantor yang lainnya dapat termotivasi untuk meningkatkan kedisiplinannya agar hasil kinerjanya bagus. Apabila ada yang melanggar aturan yang telah ditetapkan oleh kepala Kantor, bapak Ir. Nuril Anwar, M.MA memberikan sanksi kepada pegawai tersebut dengan cara memberi pengarahan agar pegawai tersebut tidak melakukan kesalahan yang sama lagi. Hal ini sesuai dengan teori yang dikemukakan oleh Warni (2016) terdapat tiga langkah yang bisa dilakukan untuk meningkatkan kedisiplinan pegawai, di antaranya: (1) Menciptakan Lingkungan Kerja yang Kondusif; (2) Penghargaan dan Sanksi; dan (3) Pelatihan secara periodik.

\section{KESIMPULAN DAN SARAN}

\section{Kesimpulan}

Jumlah pegawai yang berada di Kantor Perpustakaan dan Arsip Pemerintah Kota Probolinggo terdiri dari 34 pegawai yang terdiri dari: 1 (satu) Kepala Kantor, 1 (satu) Kepala Sub Bagian TU, 3 (tiga) orang Kepala Seksi, 5 (lima) orang tenaga Fungsional dan 24 (dua puluh empat) orang Staf. Terdapat 25 orang Pegawai Negeri Sipil (PNS), 8 orang Tenaga Harian Lepas (THL) dan 1 orang Tenaga kontrak. Berdasarkan dengan jenjang pendidikan terakhir yang ditempuh, dibedakan menjadi menjadi S2, S1, D3, SMA/SMK/SMEA, dan SD. Berdasarkan data kepangkatan/golongan dibedakan menjadi Pembina Tk.I / IVb, Pembina / IVa, Penata Tk.I / IIId, Penata / IIIc, Penata Muda Tk.I / IIIb, Penata Muda / IIIa, Pengatur Tk.I / IId, Pengatur / IIc, Pengatur Muda Tk.I / IIb, Pengatur Muda / IIa.

Tugas dan fungsi pegawai Kantor Perpustakaan dan Arsip Kota Probolinggo sudah disesuaikan menurut Peraturan Walikota Probolinggo Nomor 100 Tahun 2016 tentang Kedudukan, Susunan Organisasi, Uraian Tugas dan Fungsi serta Tata Kerja Dinas Perpustakaan dan Kearsipan Kota Probolinggo menjelaskan bahwa susunan pegawai Kantor Perpustakaan dan Arsip Pemerintah Kota Probolinggo terdiri dari: (a) Kepala kantor, (b) Sekretariat yang membawahi sub bagian tata usaha dan sub bagian program dan keuangan, (c) Bidang perpustakaan yang membawahi seksi pengolahan dan pelestarian bahan pustaka, serta seksi layanan dan otomasi perpustakaan, (d) Bidang kearsipan yang membawahi seksi pengelolaan arsip dinamis, dan seksi pengelolaan arsip statis, (e) Bidang pembinaan dan pemasyarakatan perpustakaan dan kearsipan yang membawahi seksi pembinaan dan pengembangan 
perpustakaan, seksi pembinaan dan pengembangan kearsipan, dan seksi pemasyarakatan perpustakaan dan kearsipan.

Tingkat kedisiplinan pegawai Kantor Perpustakaan dan Arsip Kota Probolinggo sudah tinggi. Dalam membentuk kedisiplinan pegawai, diperlukan sebuah strategi agar kedisiplinan pegawai kantor Perpustakaan dan Arsip Kota Probolinggo tidak mengalami penurunan. Banyak strategi yang dilakukan oleh Kepala Kantor Perpustakaan dan Arsip Kota Probolinggo, salah satu strategi yang dilakukan yaitu dengan melakukan evaluasi terhadap target kinerja pegawai, diadakannya pembinaan kepada seluruh staf dan pegawai setiap bulannya, dan tiap tahun ada SKP (Sasaran Kinerja Pegawai). Kepala Perpustakaan dan Arsip dalam menjalankan tugas dan fungsinya sebagai kepala kantor sudah berlaku adil kepada semua pegawai yang berada di kantor Perpustakaan dan Arsip Kota Probolinggo dengan memberikan tugas kepada pegawai sesuai dengan tugas dan fungsi masing-masing jabatan, sehingga tidak membebani tugas kerja pegawai lainnya. Apabila terdapat pegawai yang kinerja bagus akan diberi penghargaan berupa pegawai tersebut akan dikirim ke BKD sehingga pegawai tersebut akan mendapatkan hadiah.

\section{Saran}

Berdasrkan kesimpulan dari penelitian ini, diajukan beberapa saran bagi (1) Kepala Perpustakaan dan Arsip Pemerintah Kota Probolinggo memberikan pembinaan melalui rapat yang diadakan tiap bulan kepada pegawai, memberikan penghargaan kepada pegawai yang kinerjanya bagus, bersikap adil kepada seluruh pegawai yang berada di Kantor Perpustakaan dan Arsip Pemerintah Kota Probolinggo sehingga pegawai merasa dihargai sebagai bawahan dan meningkatkan kinerja mereka. (2) Pegawai Kantor Perpustakaan dan Arsip Pemerintah Kota Probolinggo mempertahankan kedisiplinan kerja dengan cara datang tepat waktu, melakukan semua tugas dan fungsi sesuai dengan jabatannya, serta menjalin komunikasi yang baik dengan kepala kantor maupun dengan pegawai lainnya dan dengan adanya penghargaan yang diberikan kepala kantor kepada pegawai yang berprestasi, diharapkan para pegawai kantor semakin memiliki motivasi dalam bekerja sehingga disiplin kerja tidak menurun.

\section{DAFTAR RUJUKAN}

Fachri, H. 2009. Faktor-faktor yang Mempengaruhi Disiplin Kerja Pegawai di RRI Pontianak. Jurnal Disiplin Kerja Karyawan, (Online):88, (http://pusdatin.rri.co.id)

Hidayatullah, M. F. 2010. Pendidikan Karakter: Membangun Peradaban Bangsa. Surakarta: Yuma Pustaka.

Peraturan Walikota Probolinggo Nomor 100 Tahun 2016 tentang Kedudukan, Susunan Organisasi, Uraian Tugas dan Fungsi serta Tata Kerja Dinas Perpustakaan dan Kearsipan Kota Probolinggo. Jaringan Dokumentasi dan Informasi Hukum Provinsi Jawa Timur Republik Indonesia. (Online), (http://kotaprobolinggo.jdih.jatimprov. go.id)

Saydam, G. 2000. Manajemen Sumber Daya Manusia (Human Resources Management Jilid 2). Jakarta : PT Toko Gunung Agung

Setyaningdyah, E. 2013. The Effects of Human Resource Competence, Organizational Commitment and Transactional Leadership on Work Discipline, Job Satisfaction and Employee's Performance. Interdisciplinary Journal of Contemporary Research in Business, (Online), 5 (4): 140, (http://ijcrb.webs.com)

Standar Nasional Perpustakaan Nomor 003 Tahun 2011 tentang Standar Nasional Perpustakaan Umum Kabupaten/ Kota. Perpustakaan Nasional Republik Indonesia. (Online), (http://old.perpusnas.go.id)

Warni. 2016. Bagaimana Meningkatkan Kedisiplinan Karyawan, (Online), (https://zahiraccounting.com) 